\title{
IMPLEMENTASI ALGORITMA DIJKSTRA DALAM MENENTUKAN RUTE TERPENDEK BIS TRANSJAKARTA DALAM MENGUNJUNGI 5 DESTINASI WISATA POPULER DI JAKARTA
}

\author{
Patricia Josephine Barek Baba Tapobali ${ }^{1 \S}$, Cyrenia Novella Krisnamurti ${ }^{2}$ \\ ${ }^{1}$ Program Studi Pendidikan Matematika, Fakultas Keguruan dan Ilmu Pendidikan, \\ Universitas Sanata Dharma [Email: patriciajosephine21@gmail.com] \\ ${ }^{2}$ Program Studi Pendidikan Matematika, Fakultas Keguruan dan Ilmu Pendidikan, \\ Universitas Sanata Dharma [Email: cyrenianovella@usd.ac.id] \\ ${ }^{\S}$ Corresponding Author
}

\begin{abstract}
This study shows the Dijkstra Algorithm process in determining the shortest Transjakarta bus route connecting 5 popular tourist destinations in Jakarta, namely; Ragunan Wildlife Park, Beautiful Indonesia Miniature Park, National Monument, Old Town, and Ancol Dreamland. Based on the analysis of the data obtained by the 5 shortest routes in visiting 5 popular tourist destinations in Jakarta with the initial position is a different tourist destination, namely; (1) TMII $\rightarrow$ Monas $\rightarrow$ City $\rightarrow$ Ancol $\rightarrow$ Ragunan with the length of the Transjakarta bus lane is 57.6 kilometers. (2) Ragunan $\rightarrow$ Monas $\rightarrow$ City $\rightarrow$ Ancol $\rightarrow$ TMII with the length of the Transjakarta bus lane is 47.38 kilometers. (3) Monas $\rightarrow$ City $\rightarrow$ Ancol $\rightarrow$ Ragunan $\rightarrow$ TMII with the length of the Transjakarta bus lane is 53.86 kilometers. (4) City $\rightarrow$ Ancol $\rightarrow$ Monas $\rightarrow$ Ragunan $\rightarrow$ TMII with the length of the Transjakarta bus lane is 49.46 kilometers. (5) Ancol $\rightarrow$ City $\rightarrow$ Monas $\rightarrow$ Ragunan $\rightarrow$ TMII with the length of the Transjakarta bus lane is 46.41 kilometers.
\end{abstract}

Keywords: Algoritma Dijkstra, Destinasi Wisata Populer, Graf, Rute Bis Transjakarta

\section{PENDAHULUAN}

DKI Jakarta adalah salah satu kota di Indonesia yang kaya akan objek wisatanya. Untuk mengunjungi wisata-wisata yang ada di Jakarta, para wisatawan lokal maupun non lokal kerap kali menggunakan transportasi umum Transjakarta sebagai pilihan transportasi bertamasya keliling Jakarta (Liputan6.com, 2017). Untuk menggunakan transportasi umum Transjakarta dalam mengunjungi destinasidestinasi wisata yang diinginkan, para wisatawan perlu mengetahui rute bis transjakarta terpendek dalam mengunjungi destinasi-destinasi wisata tersebut agar dapat lebih menghemat waktu. PT Transportasi Jakarta menyediakan Peta Jaringan Transjakarta pada setiap halte bis Transjakarta dan situs resmi transjakarta.co.id agar dapat mempermudah wisatawan dalam mengetahui posisi mereka berada dengan posisi destinasi wisata yang akan dikunjungi. Namun, pada peta jaringan tersebut terdapat lebih dari satu rute untuk menuju tempat tujuan dari posisi awal wisatawan berada sedangkan pada peta jaringan tersebut belum dijelaskan manakah rute yang terpendek, sehingga wisatawan kurang dapat mengetahui manakah rute terpendek untuk mengunjungi destinasi-destinasi wisata yang diinginkan.

Pada penelitian ini, akan mencoba untuk menentukan rute terpendek untuk mengunjungi 5 destinasi wisata populer di Jakarta. Tempat wisata popular di Jakarta yang menurut Badan Pusat Statistik tahun 2017 yaitu Taman Margasatwa Ragunan, Taman Mini Indonesia Indah, Monumen Nasional, Kawasan Kota Tua, dan Taman Impian Jaya Ancol, dengan menggunakan transportasi publik Transjakarta. Penelitian ini akan memberikan hasil berupa rute bis Transjakarta terpendek dalam mengunjungi 5 destinasi wisata populer tersebut dengan posisi-posisi awal merupakan destinasi wisata yang berbeda.

Algoritma Djikstra dapat digunakan dalam menentukan rute terpendek bis Transjakarta 
dalam mengunjungi suatu lokasi ke lokasi lain, yaitu dengan mengubah rute bis Transjakarta kedalam simbol-simbol matematika yang dapat dihitung dan dianalisis secara matematis. Dalam menentukan rute terpendek dari suatu jaringan transportasi, terdapat beberapa algoritma yang dapat digunakan antara lain; Algoritma Dijkstra, Algoritma Floyd-Warshall, dan Algoritma Bellman-Ford (Susani, 2012). Penelitian ini menggunakan Algoritma Dijkstra karena kesederhanaan algoritmanya yang mudah dipahami dibandingkan algoritma Floyd-Warshall dan Algoritma Bellman-Ford, estimasi waktu yang dibutuhkan dalam menjalankan program lebih cepat dibandingkan dengan Algoritma Floyd-Warshall, label pada graf yang merepresentasikan rute bis Transjakarta yang menghubungkan 5 destinasi wisata tersebut selalu merupakan bilangan tak negatif sehingga Algoritma Dijkstra lebih tepat untuk digunakan daripada Algoritma BellmanFord yang digunakan untuk graf yang memiliki label negatif dengan efisiensi waktu yang lebih lama (Nawagusti dkk, 2018). Oleh sebab itu, penelitian ini akan menggunakan Algoritma Dijkstra untuk menentukan rute terpendek bis Transjakarta dalam mengunjungi 5 destinasi wisata populer tersebut dengan menginterpretasikan rute bis Transjakarta yang menghubungkan 5 destinasi wisata tersebut kedalam suatu graf yang selanjutnya akan dianalisis menggunakan Algoritma Dijkstra.

Pokok permasalahan dalam penelitian ini adalah dibutuhkannya informasi untuk memudahkan wisatawan agar mengetahui rute terpendek bis Transjakarta dalam mengunjungi Taman Margasatwa Ragunan Taman Mini Indonesia Indah, Monumen Nasional, Kawasan Kota Tua, dan Taman impian Jaya Ancol dengan menggunakan Algoritma Dijkstra. Untuk mendukung penelitian ini terlebih dahulu merepresentasikan destinasi wisata dan rute bis Transjakarta dalam bentuk graf.

Algoritma Djikstra merupakan salah satu topic dalam Graf. Untuk membahas lebih dalam terkait algoritma Djiksta terlebih dahulu dibahas tentang Graf. Suatu Graf $G(V, E)$ adalah himpunan yang terdiri dari himpunan $V$ yaitu himpunan tak kosong titik-titik yang elemennya disebut Titik, dan himpunan garisgaris yang elemennya disebut Sisi (Siang, 2011: 276). Sebuah sisi yang menghubungkan satu titik disebut Loop, sedangkan dua sisi berbeda yang menghubungkan satu titik yang sama disebut Sisi Paralel (Wilson, 2009:08).
Graf yang tidak memiliki sisi paralel tergolong sebagai Graf Sederhana, sedangkan Graf Tak Sederhana adalah graf yang memiliki sisi paralel dan Loop (Siang, 2011:279). Jika dibedakan berdasarkan labelnya, graf terbagi menjadi dua yaitu Graf berlabel, graf yang seluruh sisinya memiliki label yaitu suatu bilangan Riil yang menyatakan bobot hubungan dari dua titik yang dihubungkan, dan Graf Tak Berlabel yaitu graf yang semua sisi pada graf tersebut tidak memiliki label (Siang, 2011:276). Jika dibedakan berdasarkan arah dari sisi-sisi pada graf, graf dibedakan menjadi dua yaitu Graf Berarah, graf yang semua sisi pada graf tersebut memiliki arah yang menunjukkan titik asal dan titik tujuan, dan Graf Tak Berarah yaitu graf yang semua sisi-sisinya tidak memiliki arah (Siang, 2011:276). Suatu Lintasan dari titik $v$ ke titik $w$ pada graf $G(V, E)$ adalah barisan titik berhubungan dan sisi secara berselang-seling (Siang, 2011:283).

Matriks adalah susunan bilangan-bilangan yang disusun dalam bentuk persegi panjang dan diatur menurut baris dan kolom (Sulistyono, 2007: 59). Matriks dapat merepresentasikan suatu graf. Menurut Siang (2011: 286), graf yang diubah kedalam bentuk matriks dapat mempermudah perhitungan-perhitungan yang diperlukan, dan matriks yang digunakan untuk merepresentasikan suatu graf pada umumnya adalah Matriks Hubung atau Adjacency Matrix. Matriks hubung adalah matriks yang setiap elemen-elemennya adalah bobot hubungan antara titik pada baris dan titik pada kolomnya. Matriks hubung yang merepresentasikan suatu graf memiliki jumlah baris dan kolom yang sama dengan jumlah titik pada graf tersebut. Misalkan $A_{n \times n}$ adalah matriks berordo $n \times n$, elemen matriks $A$ yaitu $a_{i j}$ dengan $i, j=$ $1,2,3, \ldots, n$. Elemen-elemen dari matriks hubung merepresentasikan hubungan antara baris ke- $i$ dan kolom ke- $j$ label sisi yang menghubungkan $v_{i}$ dan $v_{j}$. Apabila suatu matriks adalah representasi dari graf tak berarah, maka matriks hubung yang dibentuk adalah matriks simetris yaitu $a_{i j}=a_{j i}, \forall i, j$. Menurut Siang (2011: 299), Algoritma Dijkstra adalah algoritma yang ditemukan oleh Edsger W. Dijkstra, dan digunakan untuk menentukan jalur terpendek antara dua titik pada suatu graf. Misalkan $G$ adalah graf berlabel (berarah ataupun tidak berarah) dengan titik-titik $V(G)=\left\{v_{1}, v_{2}, v_{3}, \ldots, v_{n}\right\}$ dan jalur terpendek yang dicari adalah jalur dari $v_{1}$ ke $v_{n}$, maka 
Algoritma Dijkstra dimulai dari titik $v_{1}$. Dalam iterasinya, Algoritma Dijkstra akan mencari satu titik yang terhubung dengan $v_{1}$ dan memiliki label sisi yang paling kecil diantara titik lainnya yang juga terhubung dengan $v_{1}$. Selanjutnya titik yang terpilih pada setiap iterasi akan dipisahkan (disebut titik permanen) dan titik tersebut tidak diperhatikan lagi pada iterasi-iterasi berikutnya. Misalkan $V(G)$ adalah himpunan titik yang ada pada graf $G$ yaitu $V=\left\{v_{1}, v_{2}, v_{3}, \ldots, v_{n}\right\}, \quad L$ merupakan himpunan titik pada $V(G)$ yang sudah terpilih menjadi titik permanen, $D\left(v_{j}\right)$ merupakan jumlah bobot lintasan terkecil dari $v_{1}$ ke $v_{j}, W$ merupakan matriks hubung yang merepresentasikan graf, dan $W(i, j)$ adalah bobot sisi dari $v_{i}$ ke $v_{j}$.

\section{METODE PENELITIAN}

Penelitian ini merupakan penelitian terapan. Menurut Nawawi dan Martini (2015 : 11) menyatakan bahwa penelitian terapan adalah suatu kegiatan ilmiah yang mengungkapkan gejala alama maupun gelaja social yang terjadi dalam masyarakat, di mana dipandan perlu untuk memperbaiki suatu kejadain yang mengalami kelemahan. Peneliti melakukan penerapan dari Algoritma Dijkstra untuk menentukan lintasan terpendek bis Transjakarta dalam mengunjungi 5 destinasi wisata populer di Jakarta. Data 5 destinasi wisata populer tersebut menurut data Badan Pusat Statistik DKI Jakarta tahun 2017 adalah Taman Margasatwa Ragunan, Taman Mini Indonesia Indah, Monumen Nasional, Kawasan Kota Tua, dan Taman Impian Jaya Ancol. Objek dari penelitian ini adalah Rute bis Transjakarta yang menghubungkan 5 destinasi wisata populer tersebut.

Variabel yang digunakan dalam penelitian ini ada dua, yaitu variabel bebas dan variabel terikat. Variabel bebas dari penelitian ini adalah destinasi wisata pertama yang akan dikunjungi, sedangkan variabel terikat dari penelitian ini adalah rute terpendek bis Transjakarta dalam mengunjungi 5 destinasi wisata populer tersebut.

Teknik pengumpulan data yang digunakan dalam penelitian ini adalah menggunakan data Badan Pusat Statistik DKI Jakarta untuk memperoleh 5 destinasi wisata di Jakarta dengan jumlah pengunjung terbanyak pada tahun 2015, menggunakan situs resmi PT.
Transportasi Jakarta untuk memperoleh Peta Jaringan Transjakarta, dan Google Maps untuk memperoleh data panjang jalur bis Transjakarta yang menghubungkan halte-halte bis Transjakarta. Teknik analisis data yang dilakukan dalam penelitian ini ada dua tahap yaitu: (1) menganalisis data untuk memodelkan rute bis Transjakarta yang menghubungkan 5 destinasi wisata populer di Jakarta kedalam suatu Graf Berarah dan Berlabel dimana titik pada graf merepresentasikan halte-halte bis Transjakarta, sisi pada graf merepresentasikan jalur bis Transjakarta, arah dari sisinya menyatakan jalur bis Transjakarta yang tersedia, dan label pada sisinya menyatakan panjang jalur bis Transjakarta (2) menganalisis data menggunakan Algoritm Dijkstra untuk memperoleh rute bis Transjakarta terpendek dalam mengunjungi 5 destinasi wisata populer di Jakarta.

Untuk menentukan jalur terpendek dari $v_{a}$ ke $v_{n}$, maka langkah kerja Algoritma Dijkstra menurut Jong Jek Siang (2011: 299) adalah sebagai berikut:

1. Menentukan $v_{a}$ sebagai titik awal dan $v_{n}$ sebagai titik akhir.

2. Menentukan tabel representasi dari graf.

3. Membuat matriks hubung $W$.

4. Untuk iterasi pertama, lakukan:

a. Inisialisasi :

- $L=\{\}$

- $V(G)=\left\{v_{1}, v_{2}, v_{3}, \ldots, v_{n}\right\}$

b. Titik awal adalah $v_{a}$ maka lakukan $D\left(v_{j}\right)=\left\{\begin{array}{l}0, j=a \\ \infty, j \neq a\end{array}, \forall v_{j} \in V(G)\right.$.

c. $\forall v_{j} \in V(G)$, tentukan $D\left(v_{j}\right)$ terkecil, maka titik permanen $v_{p}$ adalah $v_{j}$.

d. $L=L \cup\left\{v_{p}\right\}$

e. Jika $v_{n} \in L$ maka iterasi berhenti, jika $v_{n} \notin L$ maka iterasi berlanjut.

5. Untuk iterasi kedua dan seterusnya, lakukan:

a. Inisialisasi :

- $L=L$

- $V(G)=V(G)-\left\{v_{p}\right\}$

b. Selanjutnya $\forall v_{j} \in V(G)$, lakukan $D\left(v_{j}\right)=\min \left(D\left(v_{j}\right), D\left(v_{p}\right)+W(p, j)\right)$.

c. Kemudian $\forall v_{j} \in V(G)$, tentukan $D\left(v_{j}\right)$ terkecil, maka titik permanen $v_{p}$ adalah $v_{j}$.

d. Diperoleh $L=L \cup\left\{v_{p}\right\}$

e. Jika $v_{n} \in L$ maka iterasi berhenti, jika $v_{n} \notin L$ maka iterasi berlanjut. 
6. Tuliskan $D\left(v_{j}\right)$ untuk $j=1,2,3, \ldots, n$ pada setiap iterasi diatas kedalam tabel.

7. Tentukan lintasan terpendeknya dengan mendaftar titik permanen pada tabel diatas mulai dari iterasi terakhir hingga iterasi pertama. Perhatikan titik permanen $v_{j}$ pada iterasi ke- $i$, apabila $D\left(v_{j}\right)$ pada iterasi ke- $i$ mengalami penurunan dibandingkan $D\left(v_{j}\right)$ pada iterasi sebelumnya, maka titik permanen pada iterasi ke- $i$ tersebut merupakan jalur yang harus dilalui.

8. Panjang Lintasan dari $v_{a}$ ke $v_{n}$ adalah $D\left(v_{p}\right)$ pada iterasi terakhir.

9. Interpretasi.

\section{HASIL DAN PEMBAHASAN}

Dari peta jaringan Transjakarta, pertama menentukan rute bis Transjakarta yang menghubungkan 5 destinasi wisata populer yang terpilih, serta panjang lintasan jalur bis Transjakarta yang berada pada rute tersebut. Peta bis Transjakarta yang menghubungkan 5 destinasi wisata populer yang terpilih dapat dilakukan dengan menggambarkan kembali peta jaringan Transjakarta dengan rute yang hanya menghubungkan 5 destinasi wisata terpilih. Sedangkan untuk menentukan panjang lintasan jalur bis Transjakarta dapat digunakan dengan mendaftar halte-halte bis Transjakarta yang berada pada rute tersebut. Selanjutnya menentukan panjang lintasan jalur bis Transjakarta antara dua halte yang berada pada jalur yang sama.

Halte bis Transjakarta terdekat dari Taman Margasatwa Ragunan adalah Halte Ragunan, halte bis Transjakarta terdekat dari Taman Mini Indonesia Indah adalah Halte TMII, halte bis Transjakarta terdekat dari Monumen Nasional adalah Halte Monas, halte bis Transjakarta terdekat dari Kawasan Kota Tua adalah Halte Kota, dan halte bis Transjakarta terdekat dari Taman Impian Jaya Ancol adalah Halte Ancol, sehingga diperoleh rute yang menghubungkan kelima destinasi wisata populer beserta nomor bis Transjakarta yang melalui rute tersebut adalah sebagai berikut:

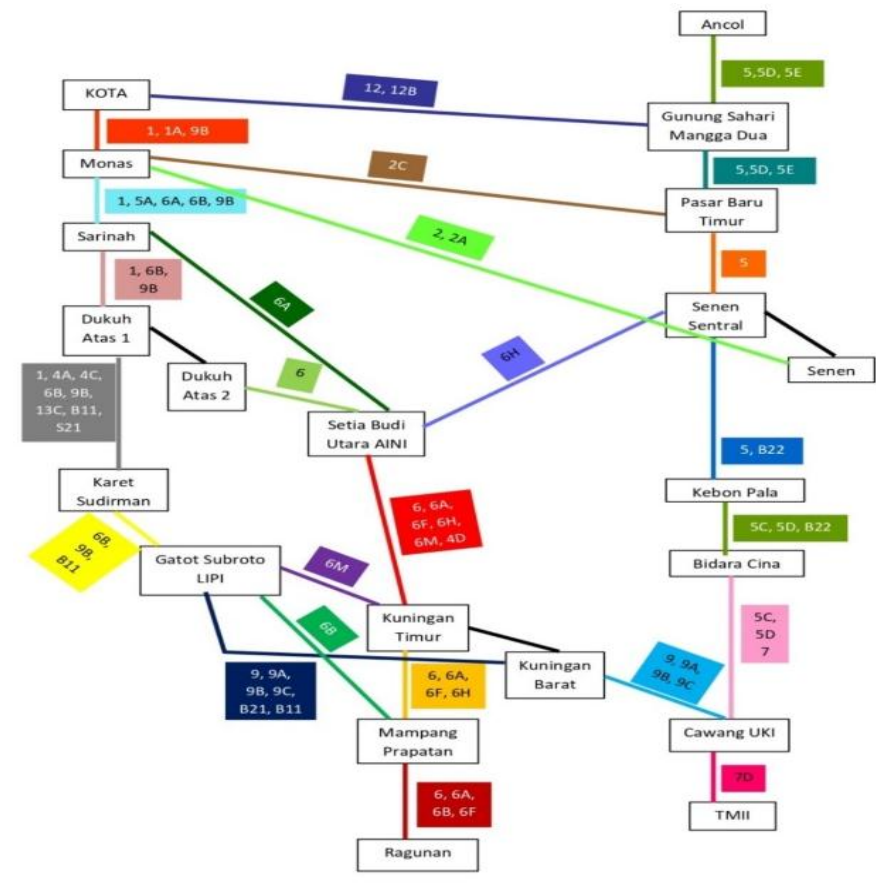

Gambar 1. Peta Jaringan Bis Transjakarta yang Menghubungkan 5 Destinasi Wisata Populer di Jakarta

Untuk menentukan panjang jalur bis Transjakarta yang ada pada peta tersebut, peneliti menggunakan Google Maps sehingga diperoeh data pada Tabel 1.

Selanjutnya, peta jaringan transjakarta yang menghubungkan 5 destinasi wisata populer tersebut direpresentasikan kedalam graf $G$. Simbol-simbol matematika adalah dengan merepresentasikan halte-halte bis Transjakarta menjadi titik-titik pada graf, jalur bis transjakarta yang tersedia menjadi sisi yang berarah pada graf, dan panjang jalur bis transjakarta menjadi label pada sisi dalam graf tersebut, maka selanjutnya dapat dibentuk suatu graf berarah dan berlabel yaitu graf $G(V, E)$ yang merepresentasikan rute bis Transjakarta yang menghubungkan 5 destinasi wisata populer di Jakarta. Penamaan titik-titik pada graf dijelaskan pada Tabel 2. 
Tabel 1. Panjang Jalur Bis Transjakarta

\begin{tabular}{|c|c|c|}
\hline Awal & Tujuan & $\begin{array}{c}\text { Panjang } \\
\text { Jalur Bis } \\
\text { Transjakarta } \\
\text { (meter) }\end{array}$ \\
\hline Ragunan & $\begin{array}{l}\text { Mampang } \\
\text { Prapatan }\end{array}$ & 7450 \\
\hline $\begin{array}{l}\text { Mampang } \\
\text { Prapatan }\end{array}$ & Gatot Subroto LIPI & 2150 \\
\hline $\begin{array}{l}\text { Mampang } \\
\text { Prapatan }\end{array}$ & Kuningan Timur & 950 \\
\hline TMII & Cawang UKI & 11810 \\
\hline Cawang UKI & TMII & 6900 \\
\hline Cawang UKI & Kuningan Barat & 7500 \\
\hline Cawang UKI & Bidara Cina & 3900 \\
\hline Kuningan Barat & Gatot Subroto LIPI & 1700 \\
\hline Kuningan Barat & Kuningan Timur & 130 \\
\hline Kuningan Timur & Gatot Subroto LIPI & 1850 \\
\hline Kuningan Timur & $\begin{array}{l}\text { Setiabudi Utara } \\
\text { AINI }\end{array}$ & 3230 \\
\hline Gatot Subroto LIPI & Karet Sudirman & 2600 \\
\hline Bidara Cina & $\begin{array}{l}\text { Kebon Pala } \\
\text { (Via Kp. Melayu) }\end{array}$ & 2050 \\
\hline Karet Sudirman & Dukuh Atas 1 & 800 \\
\hline Kebon Pala & $\begin{array}{l}\text { Bidara Cina } \\
\text { (Via Kp. Melayu) }\end{array}$ & 2300 \\
\hline Kebon Pala & Senen Sentral & 4550 \\
\hline $\begin{array}{l}\text { Setiabudi Utara } \\
\text { AINI }\end{array}$ & Kuningan Timur & 3230 \\
\hline $\begin{array}{l}\text { Setiabudi Utara } \\
\text { AINI }\end{array}$ & Dukuh Atas 2 & 3200 \\
\hline $\begin{array}{l}\text { Setiabudi Utara } \\
\text { AINI }\end{array}$ & Sarinah & 2600 \\
\hline $\begin{array}{l}\text { Setiabudi Utara } \\
\text { AINI }\end{array}$ & Senen Sentral & 6990 \\
\hline Dukuh Atas 1 & Karet Sudirman & 800 \\
\hline Dukuh Atas 1 & Dukuh Atas 2 & 300 \\
\hline Dukuh Atas 1 & Sarinah & 2000 \\
\hline Dukuh Atas 2 & Dukuh Atas 1 & 300 \\
\hline Dukuh Atas 2 & $\begin{array}{l}\text { Setiabudi Utara } \\
\text { AINI }\end{array}$ & 1310 \\
\hline Senen Sentral & $\begin{array}{l}\text { Setiabudi Utara } \\
\text { AINI }\end{array}$ & 10140 \\
\hline Senen Sentral & Senen & 56 \\
\hline Senen Sentral & Pasar Baru Timur & 2200 \\
\hline Senen & Monas & 6000 \\
\hline Sarinah & $\begin{array}{l}\text { Setiabudi Utara } \\
\text { AINI }\end{array}$ & 2600 \\
\hline Sarinah & Monas & 1400 \\
\hline Monas & Senen & 3300 \\
\hline Monas & Pasar Baru Timur & 4300 \\
\hline Monas & Kota & 4400 \\
\hline Kota & $\begin{array}{l}\text { Gunung Sahari } \\
\text { Mangga Dua }\end{array}$ & 2300 \\
\hline Pasar Baru Timur & Senen Sentral & 2200 \\
\hline Pasar Baru Timur & Monas & 3400 \\
\hline Pasar Baru Timur & $\begin{array}{l}\text { Gunung Sahari } \\
\text { Mangga Dua }\end{array}$ & 2900 \\
\hline Ancol & $\begin{array}{l}\text { Gunung Sahari } \\
\text { Mangga Dua }\end{array}$ & 1150 \\
\hline
\end{tabular}

Tabel 2. Penamaan Titik pada Graf $G(V, E)$

\begin{tabular}{|c|l|}
\hline Nama Titik & Nama Halte Bis Transjakarta \\
\hline$v_{1}$ & Kuningan Barat \\
\hline$v_{2}$ & Cawang UKI \\
\hline$v_{3}$ & TMII \\
\hline$v_{4}$ & Gatot Subroto LIPI \\
\hline$v_{5}$ & Kuningan Timur \\
\hline$v_{6}$ & Bidara Cina \\
\hline$v_{7}$ & Kebon Pala \\
\hline$v_{8}$ & Karet Sudirman \\
\hline$v_{9}$ & Ragunan \\
\hline$v_{10}$ & Mampang Prapatan \\
\hline$v_{11}$ & Setiabudi Utara AINI \\
\hline$v_{12}$ & Senen Sentral \\
\hline$v_{13}$ & Dukuh Atas 1 \\
\hline$v_{14}$ & Dukuh Atas 2 \\
\hline$v_{15}$ & Senen \\
\hline$v_{16}$ & Sarinah \\
\hline$v_{17}$ & Monas \\
\hline$v_{18}$ & Pasar Baru Timur \\
\hline$v_{19}$ & Kota \\
\hline$v_{20}$ & Gunung Sahari Mangga Dua \\
\hline$v_{21}$ & Ancol \\
\hline & \\
\hline
\end{tabular}

Dengan demikian, Graf yang merepresentasikan rute bis Transjakarta yang menghubungkan 5 destinasi wisata populer di Jakarta dituliskan sebagai Graf Tak Sederhana, Berarah, dan Berlabel yang selanjutnya disebut Graf $G(V, E)$.

Untuk menentukan rute terpendek bis Transjakarta dalam mengunjungi 5 destinasi wisata populer di Jakarta terdsebut, perlu ditentukan rute terpendek bis Transjakarta dari halte-halte bis Transjakarta terdekat dari destinasi wisata, menuju halte-halte bis Transjakarta terdekat dari destinasi wisata lainnya menggunakan Algoritma Dijkstra sehingga dapat diperoleh panjang lintasannya sebagai berikut:

Tabel 3. Panjang Jalur bis Transjakarta antar Destinasi Wisata

\begin{tabular}{|l|c|c|c|c|c|}
\hline Dari & $\begin{array}{c}\text { TMII } \\
\text { (meter) }\end{array}$ & $\begin{array}{c}\text { Ragunan } \\
\text { (meter) }\end{array}$ & $\begin{array}{c}\text { Monas } \\
\text { (meter) }\end{array}$ & $\begin{array}{c}\text { Kota } \\
\text { (meter) }\end{array}$ & $\begin{array}{c}\text { Ancol } \\
\text { (meter) }\end{array}$ \\
\hline TMII & & 27840 & 26670 & 29710 & 28560 \\
\hline Ragunan & 22930 & & 15630 & 20030 & 23480 \\
\hline Monas & 21006 & 15630 & & 4400 & 7850 \\
\hline Kota & 25050 & 20030 & 4400 & & 3450 \\
\hline Ancol & 23900 & 23080 & 7450 & 3450 & \\
\hline
\end{tabular}

Kemudian tentukan rute bis Transjakarta terpendek dalam mengunjungi 5 destinasi wisata populer di Jakarta dengan posisi awal adalah masing-masing destinasi wisata dengan proses sebagai berikut: 
1. Untuk iterasi pertama lakukan:

- $A=$ Destinasi wisata pertama yang dikunjungi

- Membuat tabel panjang lintasan bis Transjakarta dengan menghapus kolom yang memuat $A$.

- Pilih halte $B$ yang memiliki panjang lintasan terpendek terhadap halte $A$.

- Rute terdekat: $A \rightarrow B$

2. Untuk iterasi kedua lakukan:

- Membuat tabel panjang lintasan bis Transjakarta dengan menghapus kolom yang memuat $A$ dan $B$.

- Pilih halte $C$ yang memiliki panjang lintasan terpendek terhadap halte $B$.

- Rute terdekat: $A \rightarrow B \rightarrow C$

3. Untuk iterasi ketiga, lakukan:

- Membuat tabel panjang lintasan bis Transjakarta dengan menghapus kolom yang memuat $A, B$, dan $C$.

- Pilih halte $D$ yang memiliki panjang lintasan terpendek terhadap halte $C$.

- Rute terdekat: $A \rightarrow B \rightarrow C \rightarrow D$

4. Untuk iterasi keempat, lakukan:

- Membuat tabel panjang lintasan bis Transjakarta dengan menghapus kolom yang memuat $A, B, C$, dan $D$.

- Pilih halte $E$ yang memiliki panjang lintasan terpendek terhadap halte $D$.

- Rute terdekat: $A \rightarrow B \rightarrow C \rightarrow D \rightarrow E$

Dengan menggunakan algoritma diatas, diperoleh 5 rute bis Transjakarta yang menghubungkan 5 destinasi wisata populer di Jakarta dengan posisi awal merupakan halte bis transjakarta terdekat dari destinasi wisata yang berbeda yaitu rute terpendek pertama dimulai dari HalteTMII, rute terpendek kedua dimulai dari Halte Ragunan, rute terpendek ketiga dimulai dari Halte Monas, rute terpendek keempat dimulai dari Halte Kota, dan rute terpendek kelima dimulai dari Halte Ancol. Berikut adalah 5 rute bis Transjakarta dalam mengunjungi 5 destinasi wisata populer di Jakarta dengan posisi awal merupakan halte bis Transjakarta terdekat dari destinasi wisata yang berbeda-beda beserta panjang lintasannya.
Tabel 4. Rute Terpendek dan Panjang Lintasan

\begin{tabular}{|c|c|c|}
\hline Rute & Rute Destinasi Wisata & $\begin{array}{c}\text { Panjang Lintasan } \\
(\mathbf{K m})\end{array}$ \\
\hline 1 & TMII $\rightarrow$ Monas $\rightarrow$ Kota $\rightarrow$ Ancol $\rightarrow$ Ragunan & $\mathbf{5 7 , 6}$ \\
\hline 2 & Ragunan $\rightarrow$ Monas $\rightarrow$ Kota $\rightarrow$ Ancol $\rightarrow$ TMII & $\mathbf{4 7 , 3 8}$ \\
\hline 3 & Monas $\rightarrow$ Kota $\rightarrow$ Ancol $\rightarrow$ Ragunan $\rightarrow$ TMII & $\mathbf{5 3 , 8 6}$ \\
\hline 4 & Kota $\rightarrow$ Ancol $\rightarrow$ Monas $\rightarrow$ Raguman $\rightarrow$ TMII & $\mathbf{4 9 , 4 6}$ \\
\hline 5 & Ancol $\rightarrow$ Kota $\rightarrow$ Monas $\rightarrow$ Raguman $\rightarrow$ TMII. & $\mathbf{4 6 , 4 1}$ \\
\hline
\end{tabular}

\section{KESIMPULAN DAN SARAN}

Berdasarkan penelitian yang telah dilakukan, dapat disimpulkan bahwa (1) Hasil memodelkan rute bis Transjakarta yang menghubungkan 5 destinasi wisata populer di Jakarta ke dalam bentuk graf yaitu :

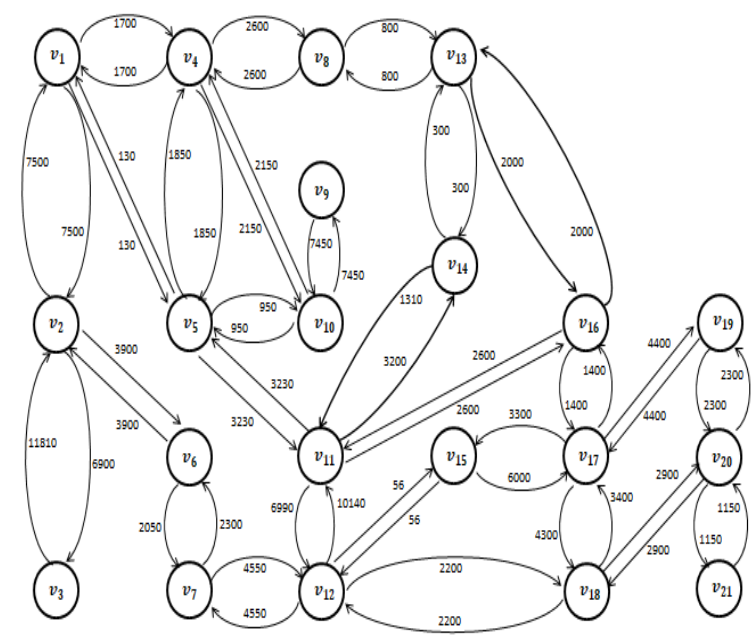

Gambar 2. Graf $G(V, E)$

.(2) cara menentuka rute terpendek bis Transjakarta dalam mengunjungi 5 destinasi wisata populer di Jakarta adalah dengan menggunakan Algoritma Dijkstra untuk menentukan rute terpendek dari setiap halte bis Transjakarta terdekat dengan masing-masing destinasi wisata, ke setiap halte bis Transjakarta terdekat dengan masing-masing destinasi wisata lainnya, kemudian dengan menggunakan rute dan panjang lintasan bis Transjakarta yang diperoleh, menentukan urutan destinasi wisata yang terpilih sehingga diperoleh 5 rute bis Transjakarta yang dapat dilakukan dalam mengunjungi 5 destinasi wisata populer di Jakarta dengan posisi awal merupakan 5 halte bis Transjakarta terdekat dengan destinasi wisata. 


\section{DAFTAR PUSTAKA}

Arikunto, Suharsimi. 2006. Prosedur Penelitian Suatu Pendekatan Praktek. Jakarta: PT. Rineka Cipta

Arikunto, Suharsimi. 2010. Managemen Penelitian Edisi Revisi. Jakarta: Rineka Cipta

Badan Pusat Statistik DKI Jakarta. Jumlah Kunjungan Wisatawan ke Obyek Wisata Unggulan Menurut Lokasi Tahun 20112015. Diakses pada tanggal 28 Januari 2019 dari https://jakarta.bps.go.id/statictable/2017/01/ 30/158/jumlah-kunjungan-wisatawan-keobyek-wisata-unggulan-menurut-lokasi2011-2015.html

Fauzi, Imron. 2011. Penggunaan Algoritma Dijkstra dalam Pencarian Rute Tercepat dan Terpendek (Studi Kasus pada Jalan raya antara Wilayah Blok $M$ dan Kota). Skripsi Program Studi Teknik Informatika, Universitas UIN Syarif Hidayatullah, Jakarta.

Kountur, Ronny. 2003. Metode Penelitian untuk Penulisan Skripsi dan Tesis. Jakarta: Penerbit PPM.

Liputan6.com. 2017. Liburan Tahun Baru, Transjakarta jadi Transportasi Favorit warga. Diakses tanggal 1 Juni 2019 dari https://www.liputan6.com/citizen6/read/26 93270/liburan-tahun-baru-transjakarta-jaditransportasi-favorit-warga

Narbuko, Cholid dan H. Abu Achmadi. 2007. Metodologi Penelitian. Jakarta: BUMI AKSARA
Nawagusti, Vera Apriliani dkk. 2018. Penentuan Rute Terpendek pada Optimalisasi Jalur Pendistribusian Barang di PT.X dengan Menerapkan Algoritma Floyd-Warshall. Seminar Nasional Inovasi dan Aplilkasi Teknologi di Industri 2018: ISSN 2085-4218. ITN Malang: 3 Februari 2018.

Nawawi, H. Hadari \& H. Mimi Martini. 2005. Penelitian Terapan. Yogyakarta: Gadjah Mada University Press.

PT. Transportasi Jakarta. 2017. Peta Jaringan Transjakarta. Diakses tanggal 18 Februari 2019 dari http://transjakarta.co.id/peta-rute/

Setiadji. ---.Pengantar Teori Graf. Bahan Kuliah Jurusan Matematika, Fakultas Matematika dan Ilmu Pengetahuan Alam, Universitas Gadjah Mada, Yogyakarta.

Siang, Jong Jek. 2011. Riset Operasi Dalam Pendekatan Logaritmis. Jakarta: Penerbit Andi.

Sulistyono. 2007. Seri Pendalaman Materi Matematika SMA dan MA. Jakarta: Penerbit Erlangga.

Suryadi H.S. 1994. Teori Graf Dasar. Jakarta: Penerbit Gunadarma.

Susani, Indriyani Mulyawatik. 2012. Perbandingan Algoritma Dijkstra, Bellman-Ford, dan FloydWarshall untuk Mencari Rute terpendek (The Shortest Lintasan Problem). Skripsi Program Studi Matematika, Fakultas Sains dan Teknologi, Universitas Islam Negeri Sunan Kalijaga, Yogyakarta.

Wilson, Robin J. 2009. Pengantar Teori Graf Edisi Kelima. Jakarta: Penerbit Erlangga. 